\title{
Implementation of three gamma measuring stations on the Colentec loop in Cadarache for the on line observation of the clogging phenomena in Steam Generator
}

\author{
L. LOUBET ${ }^{(1)}$ (laurent.loubet@cea.fr), P.G. ALLINEI ${ }^{(1)}$, P. SCHINDLER ${ }^{(2)}$, V. POINTEAU(2) \\ (1) CEA , DEN , Cadarache, DTN, SMTA, Nuclear Measurement Laboratory, F-13108 Saint-Paul-Lez-Durance, \\ France \\ (2) CEA , DEN , Cadarache, DTN , SMTA , LETH, F-13108 Saint-Paul-Lez-Durance, France
}

\begin{abstract}
The Tube Support Plate blockage, also named clogging, is a complex phenomenon that can occur in the steam generator of Pressurized Water Reactors. This deposit of iron oxides, that can reduce the coolant flux and constraint the primary tubes, could have significant consequences on heat exchanges and the integrity of the primary tubes. Since 2014, an experimental program carried out jointly by CEA-EDF, has been performed on a representative dedicated equipment, the COLENTEC loop at Cadarache. The physico-chemical properties of the deposit formed (chemical composition, thickness...) were determined at the end of each experimental campaign lead at thermohydraulic and chemical stable conditions. ...
\end{abstract}

In order to determine the influence on clogging of parameters such as the chemistry, the temperature, the pressure in an on line process and without performing separate experimental campaigns, a method of measurement on radioactive tracer, the gamma emitter ${ }^{59} \mathrm{Fe}$, has been studied by our laboratory.

First, a modelization with a monte carlo code, MCNP, has been carried out with the geometrical configuration of the Tube Support Plate zone of COLENTEC in order to determine the most adapted measuring station. These calculations had shown that a $30 \%$ efficiency, high purity, germanium detector, with a specific collimation would be able to detect the accumulation of ${ }^{59} \mathrm{Fe}$ in the Tube Support Plate of COLENTEC.

Then, in order to improve and ensure those important online measurements, our laboratory has proposed the installation of two additional measuring stations. One will be dedicated to a second on-line measurement, with a gamma detector of the same type, but positioned on a section of the loop remote from the previous area, to verify that there is no significant secondary deposit evolution elsewhere on the circuit. The last additional gamma measurement station will consist of a low background system able to carry out ${ }^{59} \mathrm{Fe}$ concentration measurements of liquid samples taken from the loop during the test.

This paper presents the context of this experiment and then focuses on the spectrometry measuring stations, modelizations and tests.
Index Terms-Clogging, gamma spectrometry, test loop, measuring station, modelization, one line measurements, steam generator

\section{INTRODUCTION - GENERAL CONTEXT}

In pressurized water plants, the transfer of heat from the primary circuit fluid to the secondary circuit takes place in the Steam Generators. Any degradation of this heat exchange can have consequences for the safety and performances of reactors. This is why, for more than 10 years, Electricity of France (EDF) and the Alternatives Energy and Atomic Energy Commission (CEA) have launched an R \& D collaborative program in order to investigate the reasons of the specific Tube Support Plate (TSP) blockage phenomenon [1]. As can be specifically seen on picture below, this phenomenon could appear in case of accumulation of clogging deposit (mainly composed of magnetite $\mathrm{Fe}_{3} \mathrm{O}_{4}$ ) in the area between the tube and the tube support plate.

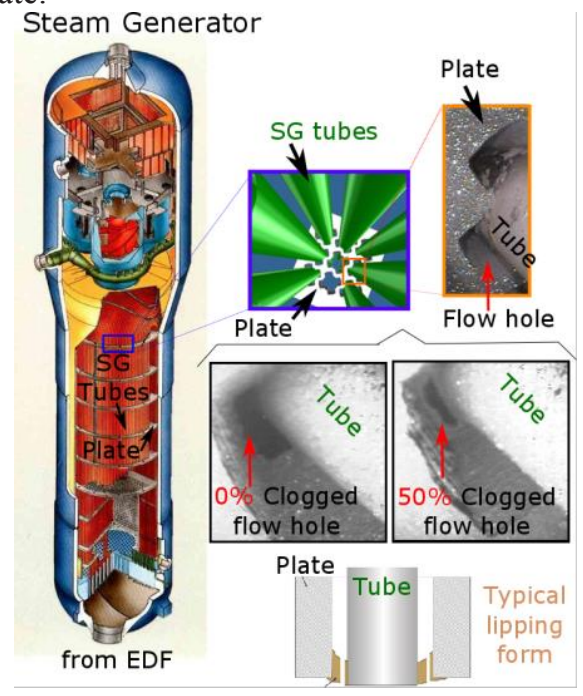

Figure 1: Clogging phenomena in PWR's SG (EDF source) 
Studies have shown that this accumulation of such a deposit is a long run phenomenon mainly influenced by the chemistry and the thermohydraulic conditions in the circuits. In a preventive way for PWR, it is then important to determine what should be the conditions to avoid or to slow down those mechanisms [1].

The specific COLENTEC's installation in Cadarache (France) allows such analyses. COLENTEC is composed of three thermodynamical loops that allow recreating the twophase flow present in the secondary side of a SG at the upper tube support plate level. The SG mock up is geometrically representative of a TSP's fraction containing 4 primary tubes (Figure 2). The TSP has been designed with movable test coupons in the four quatrefoils to ensure the possibility to characterize the deposits on surfaces.
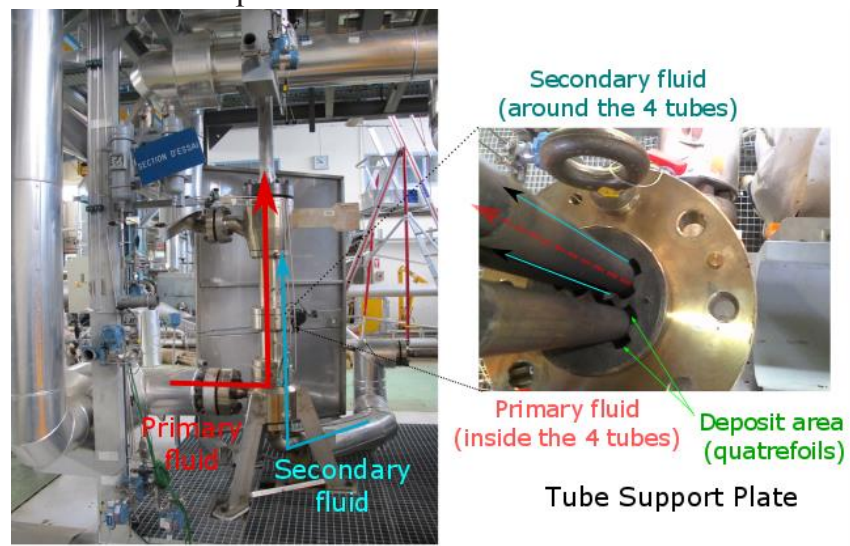

Zoom on COLENTEC

Figure 2: COLENTEC set up and the SG mock up associated

A detailed description of COLENTEC is given in ref [2]. The first experimental phase (2014-2017) had been realized in a sequential mode with the following main steps :

- Preparation and set up of the test section in the TSP,

- Enclosure and conditioning of the loops for the selected themohydraulic and chemical conditions (temperature, pressure, secondary fluid velocity, pH...),

- Stabilization for equilibrium in those conditions for few days permitting the accumulation of the deposit,

- Stop the operation and back to nominal conditions to extract the test section and characterize the deposits.

All those results have confirm the capability of the COLENTEC's installation to recreate deposits in the flow holes [3].

\section{TOWARD A NUCLEAR MEASUREMENT OF THE PHENOMENA}

Those first results from COLENTEC are very interesting and promising. Whatever, because of this sequential mode of experiment, one should have to wait the end of a campaign and the disassembly of the test section to determine a posteriori the final deposit in a chosen configuration. In order to optimize those investigations the COLENTEC's installation had been adapted for an "on-line" mode with a radioactive tracer directly injected in the secondary circuit. It becomes then possible to follow the deposit rates as a function of time and to determine the evolution of this kinetic in various configurations. This would be realized during the test, with no needs to stop and open the circuits.

The ${ }^{59} \mathrm{Fe}$ has been selected as the radioactive tracer for this phenomenon, both for its chemical representativeness of the deposit and for its gamma emission. ${ }^{59} \mathrm{Fe}$ is an energetic $\gamma$-Ray emitter. It has 2 peaks greater than $1 \mathrm{MeV}$, one at $1099 \mathrm{keV}$ (56\%) and another at $1291 \mathrm{keV}(44 \%)$ that can be then easily detected, clearly separated. Those peaks are significatively different of the gamma rays usually found in natural background. In addition, this isotope as a short period (44.495 days) that allows an easier management of the radioactive area and wastes. It has been then decided to transform the COLENTEC's equipement for this active configuration [4]. Then, the liquid ${ }^{59} \mathrm{Fe}$ source injected in the secondary circuit in a selected configuration will progressively generate the radioactive deposit.

In those conditions, with our experience in nuclear measurements, our lab has then realized the implementation of the gamma measuring station to follow the evolution of this radioactive clogging deposit.

\section{GAMMA MEASURING STATIONS}

As explained above, the main deposit occurs in the TSP, in the reduced area of the quatrefoils around the SG tubes. On the COLENTEC's installation, this deposit of the radioactive ${ }^{59} \mathrm{Fe}$ will be located in the test section, which is a scale mock-up of a real TSP with 4 SG tubes. The heart of the on line gamma measuring station had to be design for the following of the ${ }^{59} \mathrm{Fe}$ deposit in this area.

For a performing conception of this measuring station, we have taken into account the previous results. They have shown that in some cases, an additional deposit could be observed along the inner walls of the circuit (fouling). For this reason, we have decided to design a secondary gamma measuring station in order to detect on line the presence and the evolution of a possible fouling inside the circuit itself.

Finally, for an efficient management of the experimental active phase, we have proposed to use a third measuring gamma station dedicated to measure of ${ }^{59} \mathrm{Fe}$ concentrations on punctual samples taken from the fluid after the radioactive injections.

In the current design, the following of the deposit rates of ${ }^{59} \mathrm{Fe}$ in the TSP during an active campaign is illustrated on the following figure with the main steps:

1. Selection of the specific conditions (temperature, pressure, fluid velocity, $\mathrm{pH} . .$.

2. Preparation of the solution with the selected 
concentration in radioactive tracer ${ }^{59} \mathrm{Fe}$.

3. Injection of the radioactive solution inside the secondary circuit

4. Gamma measurements

a. Of the main ${ }^{59} \mathrm{Fe}$ deposit in the area of the quatrefoils of the TSP with on line acquisitions on the first detector

b. Of the secondary ${ }^{59} \mathrm{Fe}$ deposit inside the circuit with on line acquisitions with the second detector

c. Of the average ${ }^{59} \mathrm{Fe}$ activity of the fluid in the circuit from a sample taken from the circuit and transferred toward the third detector

5. On line tracking of the deposit kinetics until the equilibrium is established

6. Preparation for new specific conditions (no use to stop or open the installation) and back to step 1 .

The three gamma measuring stations used during this active campaign could be located on the picture below.

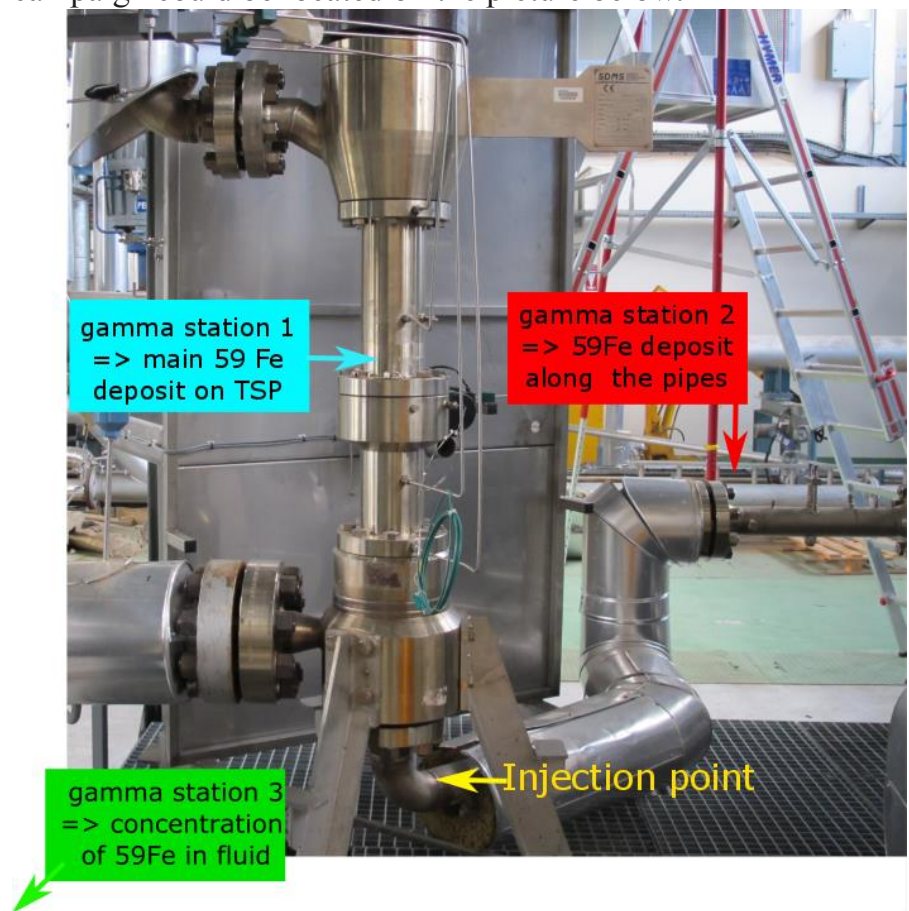

Figure 3: Schematic configuration of the gamma measuring stations

We have designed those three gamma measuring stations. The three following paragraphs describe their dimensioning, starting from the simpliest (measurement of the iron's concentration in the fluid) until the most complex (following the iron deposit inside the TSP).

\section{IMPLEMENTATION OF THE ${ }^{59} \mathrm{FE}$ CONCENTRATION IN THE CIRCUIT}

This gamma measuring station of a liquid sample is the simplest, based on an already existent equipment in our lab dedicated to the low level activity (HP-Ge coaxial with a
$120 \mathrm{~cm}^{3}$ cristal). For this case, a gamma High Purity germanium detector is located inside a lead shilding in order to reduce the background. It is thus possible to determine the ${ }^{59} \mathrm{Fe}$ concentration of a water sample of a given volume.

In gamma spectrometry, usually, to determine the activity of a sample, one needs to realize an efficiency calibration of gamma measuring station. This efficiency allows to convert the counts per second, obtained with the detector, at a given energy, obtained from the measurement of the selected isotope into $\mathrm{Bq}$ of the sample. Knowing this efficiency, finally, the relation between the measured surface at the energy $\mathrm{E}$ and the activity is

$$
\text { Activity }=\frac{\operatorname{Surface}(E)}{t \times I_{\text {gamma }}(E) \times E f f i c i e n c y(E)}
$$

- Activity : Activity of the sample in Bq

- $\quad$ Surface(E) : net area of the measured photopeak (peak of total absorption) at the energy $\mathrm{E}$ in the spectrum (counts)

- $\mathrm{t}$ : duration of the measurement, active time in $\mathrm{s}$

- $I_{\text {gamma }}(\mathrm{E})$ : Emission probability of the selected isotope at the energy E, obtained in tables (no unit)

- $\quad$ Efficiency $(E)$ : obtained from a standard in a given configuration

In our case, we have a direct configuration using a $50 \mathrm{~cm}^{3}$ standard bottle, with a perfectly known Activitystandart and specifically adapted for gamma spectrometry. We have measured this standard, of a given activity, in a such $50 \mathrm{~cm}^{3}$ bottle placed at the chosen distance from the detector. Surface $(E)_{\text {standart }}$ is obtained from this measurement of the standard with its known activity. We can thus calculate Efficiency(E) for this measuring configuration. Then, it will become easy to obtain the unknown sample Activitysample from a experimental Surface $(E)_{\text {sample new measurement of the same }}$ kind of water bottle placed at the same distance.

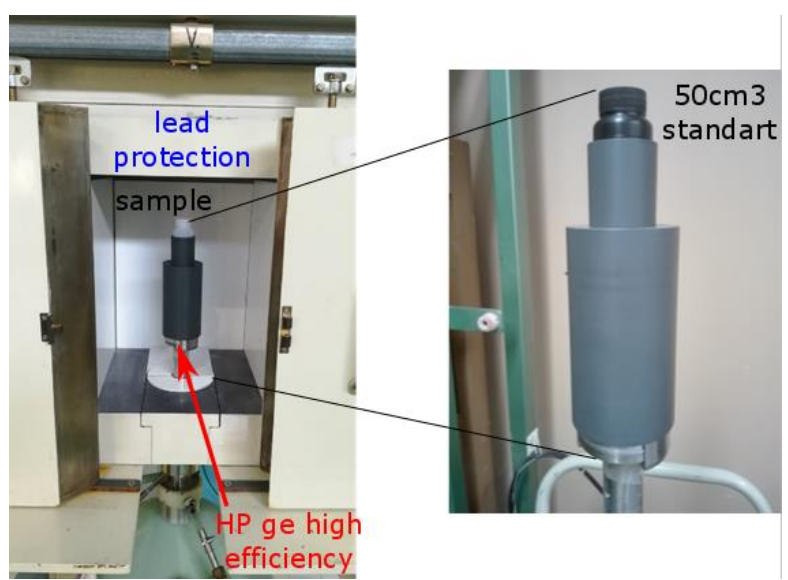

Figure 4: Low background measuring station for determination of the activity concentration in the fluid 


\section{IMPLEMENTATION OF THE ${ }^{59}$ FE FOULING ALONG THE CIRCUIT}

For this secondary measuring station of the fouling inside a pipe, we also have selected equipment we usually use in our lab for the determination of the gamma contamination (from activation products for example) inside fluid circuits such as those of PWR. From such circuits where contamination can be accumulated inside and along the pipes, we generally use a HpGe with $40 \%$ efficiency. Thanks to its high resolution, $\mathrm{HpGe}$ is then able to accurately detect specific isotopes from a given background. The intermediate selected efficiency of $40 \%$ is a good compromise, convenient for a large scale of activities in a large diversity of pipes, diameter and thickness.

In this second case, the determination of the deposed activity is less simple than in the previous case because no equivalent standard can be used. For this quantification, we then need to realize a numerical efficiency calibration. Our method to determine the activity of a given deposit in a given configuration from a gamma spectrum is to separate the "efficiency" in two terms. The first term we call the absolute efficiency and note $\mathrm{K}(\mathrm{E})$ is depending on the only detector. The second term we call the transfert function (FT) is calculated from codes for the selected measurement configuration. Thus the previous relation becomes

$$
\text { Activity }=\frac{\operatorname{Surface}(E)}{t \times I_{\text {gamma }}(E) \times(K(E) \times F T(E))}
$$

- $\mathrm{K}(\mathrm{E})$ : in $\mathrm{cm}$ is the number of counts measured at the energy $E$ for a given flux of 1 gamma $/ \mathrm{cm}$ arriving at the center of the detector. $\mathrm{K}(\mathrm{E})$ is obtained from a measurement with a punctual standard source at the distance $\mathrm{d}$ from the detector. $\mathrm{K}(\mathrm{E})$ is establish for the selected detector and is independent of the environnement.

- $\quad \mathrm{FT}(\mathrm{E})$ : in $\mathrm{cm}^{-2}$ is numerically determined as the flux of photons received at a point (center of the detector) from a massive source emitting 1 gamma in a isotopic distribution.

The transfert function for complex geometries can be calculated in numerical ways using codes such as Mercure or Microshield. The principle is to divide the massive source in multiple elementary sources that can then be considered as punctual ones. The flux emitted from each punctual source toward the calculation point is evaluate taking into account dilution in space an attenuation in encountered materials. An numerical integration for each energy gives then the FT(E).

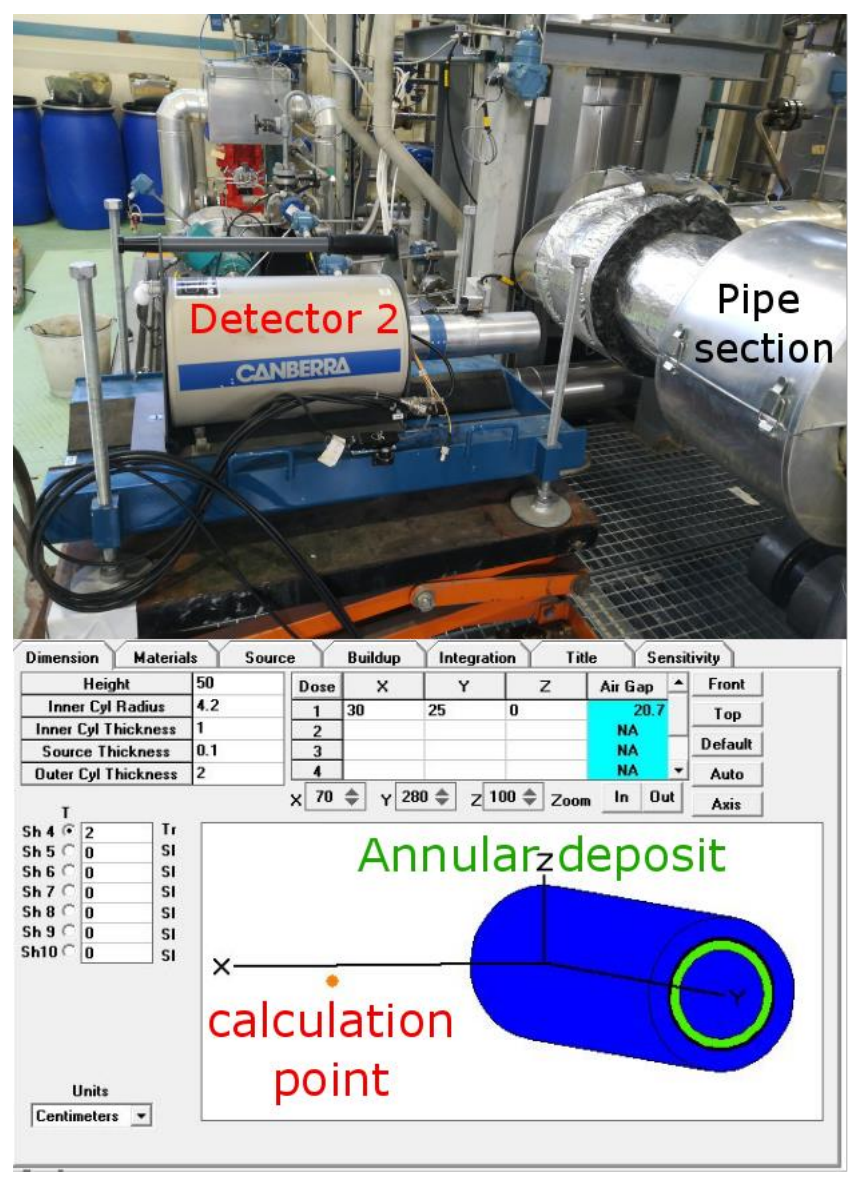

Figure 5: Deposit measuring station and example of modelization with microshield

The numerical modelization of the massive source must be as representative of the measurement configuration. One should select the distances and the dimensions of the object (here a deposit inside the pipe), the constituting materials (iron, air, water, insulaton...) their density, and then select $1 \mathrm{~Bq}$ as an activity in coherence with the previous formula. This numerical calculation then gives the FT(E). Combining FT(E), numerically determined for the measurement configuration, with the experimental absolute efficiency of the detector realized from a measurement of a punctual source, will finally give the global "efficiency". Then, the surfaces measured in real conditions and this efficiency allow to calculate the given activity of the deposit.

\section{IMPLEMENTATION OF THE ${ }^{59}$ FE DEPOSIT ON THE TSP}

This gamma measuring station of the deposit in the quatrefoils inside the TSP is the heart of the COLENTEC's system. The physical parameters (geometry, size of the $\gamma$-Ray spectrometer, shielding) have been optimized to ensure maximum detection sensitivity and optimal location of the deposition area. Due to the general environment, a low activity of ${ }^{59} \mathrm{Fe}$ in the quatrefoils with respect to the thickness of the TSP and the amount of ${ }^{59} \mathrm{Fe}$ present in the secondary fluid, the $\gamma$ measurement required a precise dimensioning [5]. 


\section{A. Selection of detector for the TSP's deposit measuring station}

The selection of the detector is describes in details in [4]. The measurement of selectively locating low levels of ${ }^{59} \mathrm{Fe}$ activity in this specific environment requires detectors family equipped with a large volume crystal (high sensitivity criterion). In addition, the selected detector has to be able to discriminate the signal coming from the active deposit from the background. The modelization of ${ }^{59} \mathrm{Fe}$ spectrum in theoretical backgroud have shown that the two main peaks of ${ }^{59} \mathrm{Fe}, 1099 \mathrm{keV}$ and $1291 \mathrm{keV}$ are clearly identifiable and quantifiable with HP-ge. This kind of detector has then been selected as the best detection system despite its constrained operating principle requiring liquid nitrogen.

\section{B. Optimization of the design of deposit with the measuring station}

In order to increase the signal/noise ratio an optimization of the design of this measuring station had been conducted in an iterative way. Taking into account the characteristics of the TSP component, the thickness of the pipe, the heat insulation, the detector have be located as near as possible of the deposit in order to increase the signal. An adapted collimation and a tungsten crown have also been designed to focus the measurement on the deposit area and to reduce the contribution of other emissions.
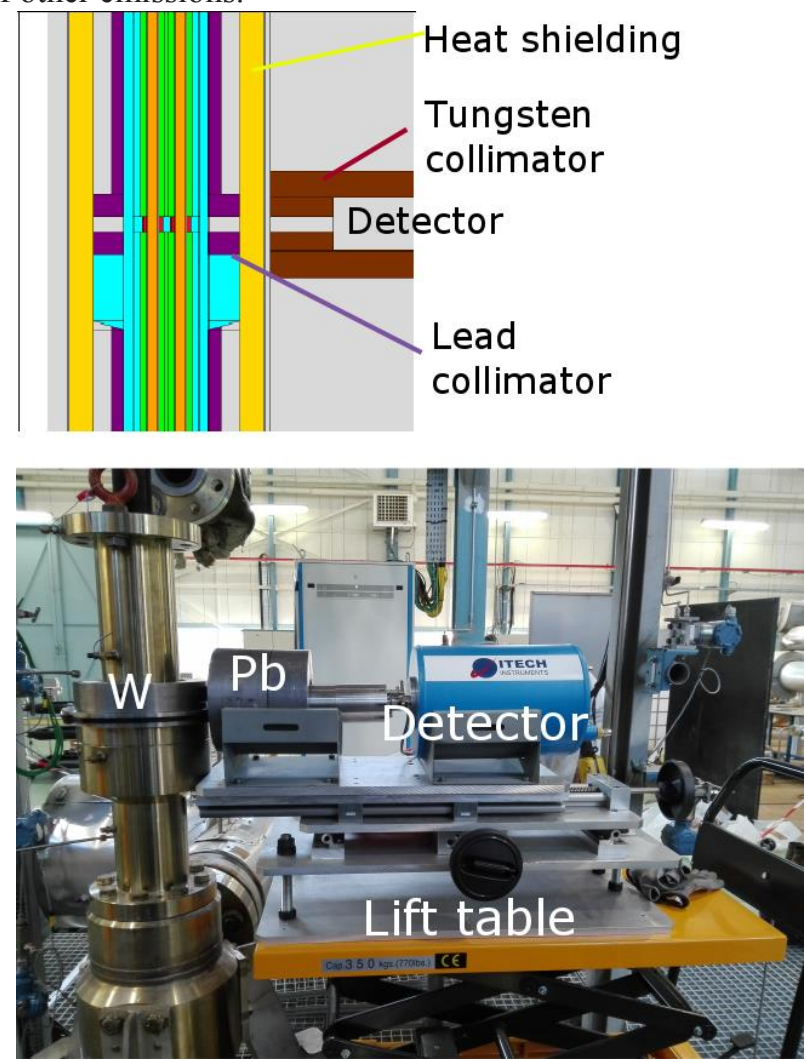

Figure $6:$ MCNP modelization of the deposit area and real picture (without heat shielding)
Finally, in this optimized configuration, theoretical spectrum had been calculated with MCNP.

Combining those results with the simulated background, made possible to determine the Detection Limit of this deposit measuring station thanks to the next formula

$$
\begin{aligned}
D L & =\frac{2 * D T}{\text { Igamma } * \text { Efficiency }} \\
& \text { - Detection Threshold : in s } \mathrm{s}^{-1} \text { calculated as }
\end{aligned}
$$

○ $\quad D T=\frac{4.4 * \sqrt{1+R * B}}{t}\left(\right.$ in s $\left.^{-1}\right)$

- $\mathrm{R}$ is the Full Width at Half Maximum of the peak (in $\mathrm{KeV}$ )

- $\mathrm{B}$ is the mean background calculated around the peak (in counts)

The unit of the DL is depending on the unit of the efficiency. In our case, we calculate an efficiency in $[$ photon $/ \mathrm{s}] / \mathrm{cm}^{3}$ in order to obtain the $\mathrm{DL}$ in $[\mathrm{Bq}] / \mathrm{cm}^{3}$

With this calculation, the expected limits of detection were:

\begin{tabular}{|l|l|l|l|}
\hline $\begin{array}{l}{ }^{59} \mathrm{Fe} \\
(\mathrm{keV})\end{array}$ & $\begin{array}{l}\text { peak } \\
\text { threshold } \\
(\mathrm{s}-1)\end{array}$ & $\begin{array}{l}\text { Detection } \\
\text { emission }\end{array}$ & $\begin{array}{l}\text { Detection } \\
\text { limit } \\
\left(\mathrm{Bq} / \mathrm{cm}^{3}\right)\end{array}$ \\
\hline 1099 & $2.5310-2$ & $56 \%$ & 58 \\
\hline 1291 & $2.1010-2$ & $44 \%$ & 61 \\
\hline
\end{tabular}

This detection limit have been considered as significative of a realistic deposit on the TSP and sufficient de follow the evolution of such a deposit in a given configuration (temperature, pressure $\mathrm{pH} . .$. ) [6].

The corresponding detector have been bought, the collimator realized and the authorizations for the passage in (radio)active configuration launched.

\section{ACTUAL SITUATION AND PROSPECTS}

The three detectors had been received, in our lab, tested and calibrated. Then a large number of pre measurements have been realized for the preparation of the active measurements on COLENTEC

Acquisitions sequences have been tested in order to confirm the capacity to realize simultaneous measurements on the two on line detectors.

Complementary inactive test with punctual gamma sources in the specific COLENTEC's environnement (heat, pump vibrations, distance between detector and computer...) have been realized. 


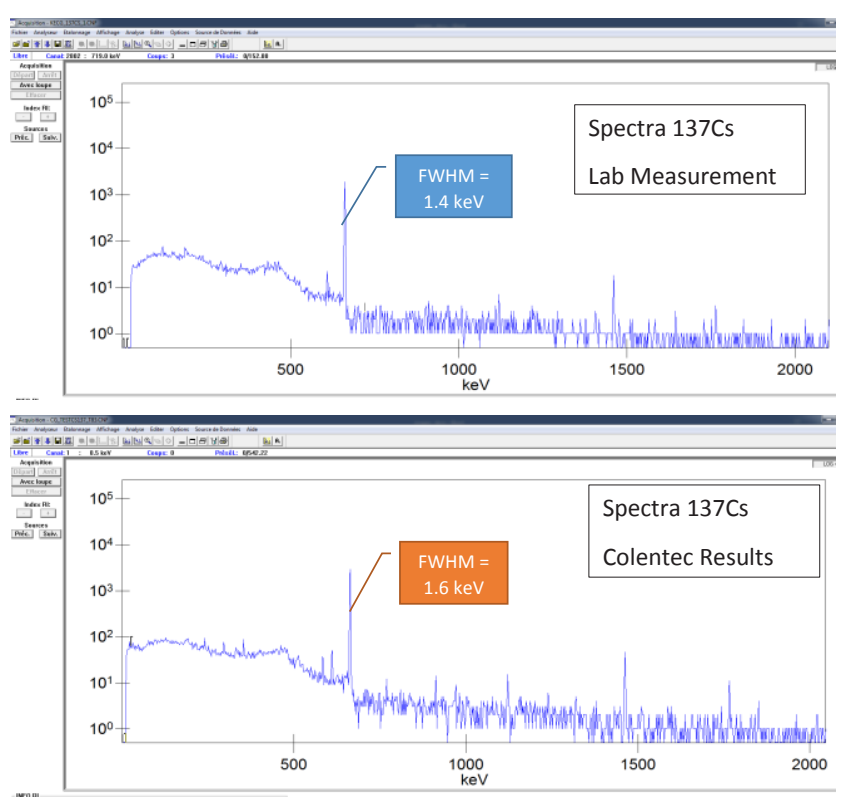

Figure 7 : Comparison of ${ }^{137}$ Cs spectra measured in our lab (left) and in the Colentec environment (right)

The comparison of spectra obtained in our lab, in classical conditions, with the same kind of measurements on punctual test source realized in the COLENTEC'S specific environment shows no significant degradations of the performances. More specifically, the LTMH on the $662 \mathrm{keV}$ coming from a ${ }^{137} \mathrm{Cs}$ test source was $1.4 \mathrm{keV}$ in the optimal conditions of our lab and became $1.6 \mathrm{keV}$ in the specific hot, vibrating and distant COLENTEC's hall.

Other realistic measurements on the COLENTEC's equipment have been realized in June 2018 with the two deposit stations, on the TSP and on the line in the inactive configuration. They confirm the coherence of the real background spectrum with the simulated one.

A first detection of ${ }^{59} \mathrm{Fe}$ has also be done in December 2018 on an ${ }^{59} \mathrm{Fe}$ sample with the low background station

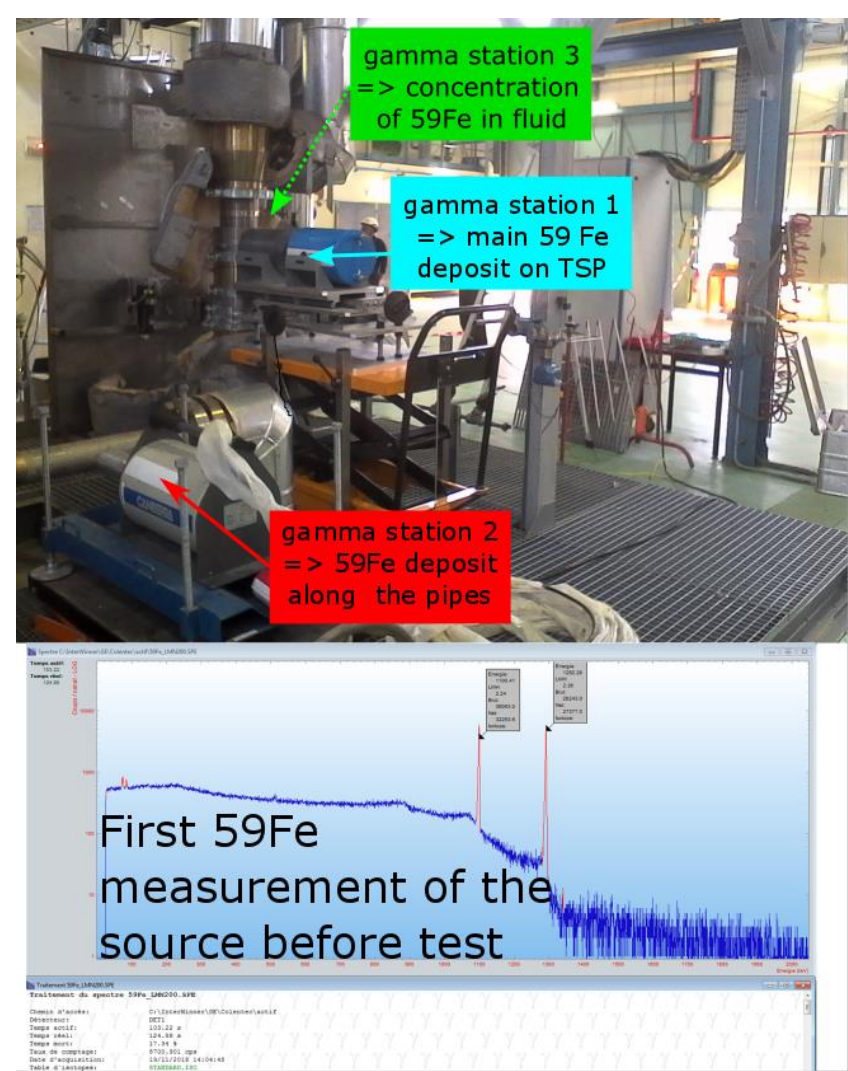

Figure 8 : First measurements campaign before injection of $59 \mathrm{Fe}$

We have finally realized the first active campaign in April 2019. The numerous and rich results obtained on this occasion have confirmed the great performances of the modelized gamma measuring stations. Analyses are on process.

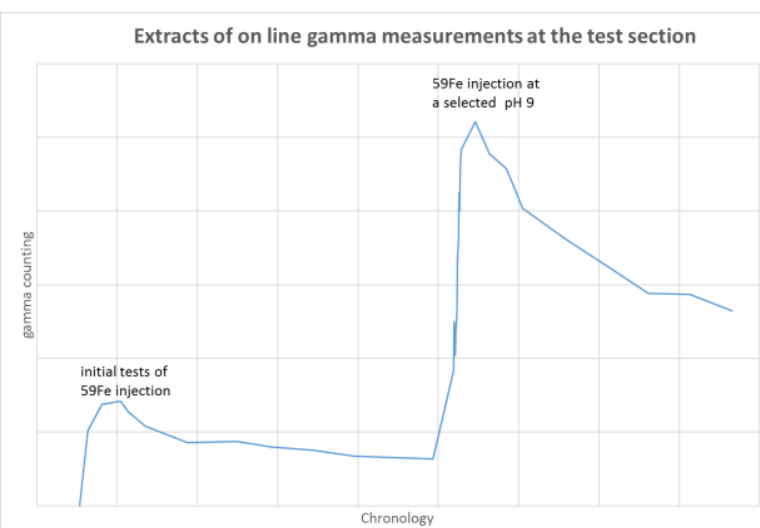

Figure 9: Abstract from first results from the gamma station 1 during an active injection of ${ }^{59} \mathrm{Fe}$ [7].

\section{ACKNOWLEDGMENT}

Thanks to Allinei P.G. and Schindler P. parents of this active configuration and to the current teams of laboratories and supports for the energy injected into this project 


\section{REFERENCES}

[1] Rummens, H.E., Rogers, J.R., Turner, C.W. 2004. The Thermal Hydraulics of Tube Support Fouling in Nuclear Steam Generator. Nuclear Technology, 148 (3), pp. 268 286.

[2] V. Pointeau, E. Tevissen, P. Schindler, A. Chagnes, Yang, J.L. Bretelle, S. Delaunay Synthesis and characterization of magnetite deposits on tube support plate in COLENTEC diphasic loop dedicated to the study of steam generator's clogging. NPC 2016, Paper reference 145.

[3] Corredera, G., Alves-Vieira, M., De Bouvier, O., 2008. Fouling and TSP blockage of steam generators on EDF fleet: identified correlations with secondary water chemistry and planned remedies. Proceeding of the International Conference on Water Chemistry of Nuclear Reactor Systems, Berlin, Germany, 2008, September 15-18.

[4] Schindler, P.G. Allinei, L. Loubet, V. Pointeau. Evolution of the Steam Generator clogging phenomena kinetics by gamma ray counting. Conference: NPC 2012, At Paris, Volume: 12 .

[5] Allinei, P.G. 2011. Dimensioning study of the measurement system associated with the Colentec loop. Personnal communication.

[6] Schindler, P. Personnal communication Journal of Nuclear Engineering and Radiation Science APRIL 2019, Vol. $5 /$ 020912-1

[7] V. Pointeau, J. Peybernes. Personnal communication 